\title{
CONFORTO TÉRMICO EM SALA DE AULA NATURALMENTE VENTILADA
}

\author{
Cláudia Rocha Guidi ${ }^{1}$ \\ Pedro Ivo Torquato Palmes ${ }^{2}$ \\ Ana Carolina de Oliveira Veloso ${ }^{3}$ \\ Roberta Vieira Gonçalves de Souza ${ }^{4}$ \\ Célia Diniz Soares Nastrini ${ }^{5}$ \\ Gustavo Antônio da Silva ${ }^{6}$
}

DOI: $10.5752 / P .2316-1752.2020 v 27 n 40 p 282$

\section{Resumo}

O conforto térmico é importante fator de aprendizado em salas de aula. Este trabalho teve como objetivo avaliar soluções

\footnotetext{
1. Arquiteta e Urbanista pela UFMG, mestre em Ambiente Construído e Patrimônio Sustentável pela UFMG, doutoranda do Programa de Pós-Graduação em Ambiente Construído e Patrimônio Sustentável pela UFMG. E-mail: claudiarguidi@gmail.com

2.Estudante do Curso de Graduação em Arquitetura e Urbanismo da UFMG. E-mail: pedropedroide@gmail.com

3. Arquiteta e Urbanista pela UFMG, mestre em Ambiente Construído e Patrimônio Sustentável pela UFMG, doutora em Engenharia Mecânica pela UFMG, pós-doutoranda do Programa de Pós-Graduação em Ambiente Construído e Patrimônio Sustentável pela UFMG. Professora do Curso de Arquitetura e Urbanismo da UNA e do curso de Pós-Graduação em Arquitetura Bioclimática da PUC Minas. E-mail: acoveloso@gmail.com

4. Arquiteta pela UFMG, mestre e doutora em Engenharia Civil pela UFSC. Professora do Departamento de Tecnologia da UFMG e do curso de Pós-Graduação em Ambiente Construído Patrimônio Sustentável. E-mail: robertavgs2@gmail.com

5. Arquiteta pela PUC Minas. E-mail: nastrini@pucminas.br

6. Engenheiro elétrico pela PUC Minas, mestre em Gestão de Riscos em Geotecnia e Desastres Naturais pela UFOP. Professor da FUMEC, PUC Minas, Pitágoras, Centro Universitário de Belo Horizonte (UNIBH), Instituto de Ensino Superior Albert Einstein, Centro Universitário Newton Paiva. E-mail: gustavo@equipaeng.com.br
} 
passivas para uma sala de aula que apresenta níveis elevados de desconforto térmico relatados por alunos e professores. Foi obtido por meio de simulações no programa EnergyPlus o percentual de horas de conforto a partir da ASHRAE 55 tanto na situação atual quanto nas quatro soluções propostas. A sala de aula obteve $50 \%$ de horas de conforto na situação atual e a solução de proteção solar com pintura branca das paredes externas foi a que obteve o melhor resultado com $61 \%$ de conforto.

Palavras-chave: Conforto térmico. Retrofit. Sala de aula. 
THERMAL COMFORT IN NATURALLY VENTILATED CLASSROOM

\begin{abstract}
Thermal comfort is an important learning factor in schools. This work had the objective of evaluating passive solutions in a classroom that presents high levels of thermal discomfort as stated by students and professors. Using EnergyPlus simulations the percentage of comfort hours according to ASHRAE 55 was obtained both for the current situation and for the four architectural solutions proposed. The classroom presented $50 \%$ of comfort hours in the current situation and the solution of brise soleil with white exterior wall paint obtained the highest percentage of comfort hours, reaching $61 \%$.
\end{abstract}

Keywords: Thermal Comfort. Retrofit. Classroom.

\section{CONFORT TÉRMICO EN AULA VENTILADA NA- TURALMENTE}

\section{Resumen}

Confort térmico es un factor importante en el aprendizaje. Este trabajo tiene como objetivo evaluar soluciones pasivas para un aula que presenta altos niveles de incomodidad térmica relatados por profesores y alumnos. El porcentaje de horas de confort de ASHRAE 55 tanto en la situación actual como en las soluciones propuestas se obtuvo a través de simulaciones en EnergyPlus. El aula obtuvo el $50 \%$ de las horas de confort en la situación actual y la solución de protección solar con pintura blanca para paredes exteriores lograran el más grande porcentaje de horas de confort, alcanzando $61 \%$.

Palabras-claves: Confort térmico. Retrofit. Aula. 


\section{Introdução}

Conforme Batiz et al (2009), existe uma relação direta entre o conforto térmico e o processo de aprendizagem, uma vez que o desconforto térmico pode reduzir a concentração ao exigir maior esforço físico e mental dos alunos. Os ambientes de salas de aula universitárias, geralmente espaços densamente ocupados, são temas de diversos trabalhos por exigirem conforto térmico e visual para o desenvolvimento de atividades, especialmente em universidades públicas, onde este tipo de ambiente é, de forma geral, condicionado naturalmente (OCHOA, ARAÚJO e SATTLER, 2012; BACICHETI, CARDOSO e SARDEIRO, 2016; VASCONCELOS, MENEZES e BARBOSA, 2017; RIZZO e SARDEIRO, 2017).

Muitos edifícios escolares existentes não apresentam níveis de conforto térmico satisfatório e, por isso, há a necessidade de realizar intervenções de modo a melhorar a qualidade ambiental interna e reduzir o consumo de energia. As edificações existentes podem e devem sofrer modificações a fim de atender às necessidades de uso de seus ocupantes (ROGERS, 1997).

O objetivo deste trabalho foi avaliar soluções passivas de propostas arquitetônicas para uma sala de aula por meio de simulação computacional a fim de melhorar o conforto térmico dos usuários. 


\section{Referencial teórico}

O estudo de Singh et al (2019) analisou o progresso no estudo do conforto térmico em salas de aula nos últimos 50 anos constataram que há necessidade de diretrizes diferenciadas para a construção de salas de aula de acordo com o nível escolar. Os autores verificaram, ainda, que, em 93 artigos recuperados da base Scopus, os alunos se mostraram altamente desconfortáveis com o ambiente térmico predominante, preferindo temperaturas mais baixas que as existentes nos ambientes de sala de aula. Com relação aos métodos de análise de conforto térmico, os autores verificaram a introdução nos últimos anos de análises por meio de métodos de conforto adaptativo.

De acordo com Keeler e Burke (2010), um dos princípios fundamentais da arquitetura sustentável é a readequação das edificações existentes. Em consonância, Heywood (2017) afirma que as reformas com o objetivo de trazer melhorias ambientais, podem reduzir significativamente o consumo de energia operacional do edifício.

Conforme o Balanço Energético Nacional (BRASIL, 2018), as edificações comerciais utilizaram $17,1 \%$ da produção nacional de energia elétrica enquanto as edificações públicas utilizaram 8,2\%. De acordo com Lamberts, Dutra e Pereira (2014), em torno de $47 \%$ do total do consumo de energia desses edifícios são para o uso do ar-condicio- 
nado. Esse tipo de condicionamento de ar ainda não é o mais presente nas salas de aula em universidades públicas, mas verifica-se uma tendência ao uso cada vez mais intensivo de ventiladores e uma inclinação à substituição progressiva por sistemas de condicionamento artificial de ar (GARCIA, 2019). Dessa forma, tornam-se essenciais estudos relativos à eficácia das soluções passivas que busquem aumento de conforto e a consequente redução da necessidade do consumo de energia em prédios existentes.

Nesse sentido, Rizzo e Sardeiro (2017) verificaram que a inserção de proteções solares (brise soleils) melhora as condições de conforto térmico em uma sala de aula. As autoras também reforçaram que devem ser analisadas soluções combinadas de tipos de proteção solar de modo a obter melhores resultados tanto para o conforto do usuário quanto para a redução do consumo energético.

Também tratando do assunto com o recorte da sala de aula, a pesquisa desenvolvida por Costa, Joko e Frederico (2017) analisou o desempenho termo energético de um prédio escolar tombado e cinco possíveis soluções para melhoria do conforto térmico e energético considerando os aspectos patrimoniais da edificação. As soluções analisadas estavam relacionadas à cobertura, já que não se poderia intervir em características estéticas da fachada. Apenas um cenário para fachada foi simulado com altera- 
ção de angulação da proteção solar existente. Os autores concluíram que as alterações reduziram os extremos de temperatura, mas não conseguiram atender ao melhor desempenho preconizado por norma. Entretanto, as soluções foram consideradas essenciais para a redução do uso de sistemas artificiais (ventiladores e ar-condicionado) a fim de alcançar melhores condições térmicas no ambiente.

À luz dessa temática, o objetivo deste trabalho é, portanto, avaliar soluções arquitetônicas para o alcance de conforto térmico em uma sala de aula de edifício universitário localizado na cidade de Belo Horizonte através da análise da ASHRAE 55 e dos limites de porcentagem de horas em conforto (POC) estabelecidos no RTQ-C.

Este artigo é resultado de um trabalho desenvolvido durante uma disciplina da pós-graduação lecionada em conjunto com disciplina para alunos da graduação de modo a inserir estes últimos no universo da pesquisa acadêmica e das técnicas de simulação computacional utilizadas tecnicamente para a comprovação de normas e legislação.

\section{Método}

O trabalho desenvolvido contempla a avaliação do conforto térmico de uma sala de aula através de simulações computacionais realizadas no programa EnergyPlus 8.7. A sala foi escolhida por apresentar constantes reclamações 
de desconforto térmico junto ao colegiado de curso por parte dos alunos da instituição de ensino universitário. A partir dos resultados obtidos, por meio de simulações computacionais, para a situação atual da sala, foram propostas quatro soluções e avaliada a combinação entre elas para minimizar o desconforto térmico.

\subsection{Objeto de estudo}

O ambiente analisado é de uma sala de aula em uma universidade localizada em Belo Horizonte - MG. A sala encontra-se no andar intermediário de um edifício de três pavimentos. A construção não apresenta pilotis, é estruturada em concreto armado com vedações externas de tijolo maciço de $15 \mathrm{~cm}$ e vedações internas de tijolo furado de $20 \mathrm{~cm}$. A cobertura consiste em uma laje de concreto coberta com telhas metálicas e as janelas são de quatro folhas, sendo duas que permitem ser abertas e duas fixas, sem bandeira superior.

Quanto à implantação, o edifício encontra-se disposto no sentido Sudoeste-Nordeste, tendo suas maiores fachadas voltadas para o Noroeste e Sudeste (FIGURA 1). A fachada Noroeste, cuja exposição solar é maior, encontra-se protegida pelo relevo por uma faixa de vegetação e por um edifício, que promovem sombreamento. Já a fachada Sudeste, na qual se situa o ambiente analisado, não há qualquer tipo de sombreamento ocasionado por 
outros edifícios ou elementos externos (FIGURA 1). A Figura a seguir evidencia a relação do edifício com o relevo e o seu entorno. O prédio em questão está destacado na cor vermelha e a sala de aula na cor azul. Na Figura 2, observa-se uma carta solar da cidade de Belo Horizonte, em que a fachada Sudeste se apresenta destacada.

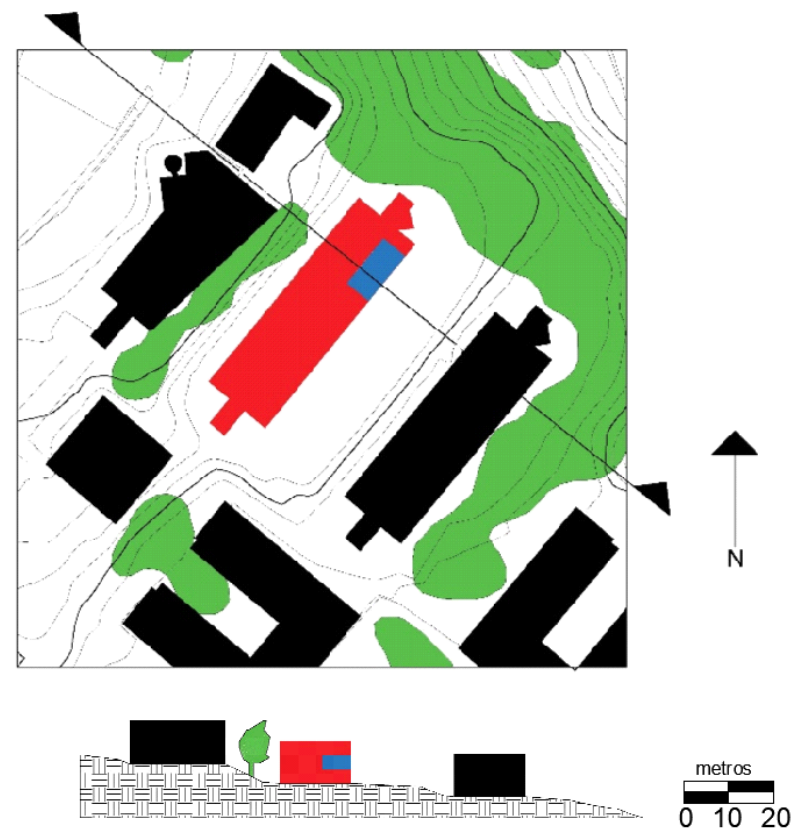

Figura 1 | Implantação e corte do edifício estudado. Fonte: Elaborada pelos autores, 2019. 


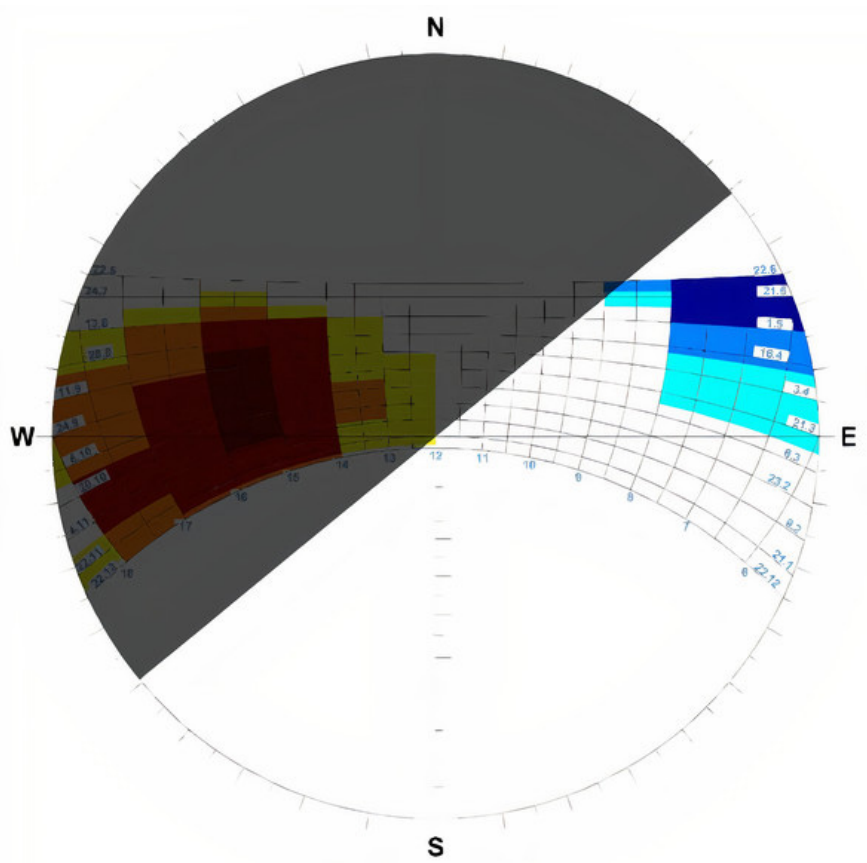

Figura 2 | Carta solar de Belo Horizonte com ênfase à fachada Sudeste. A legenda de cores indica os períodos abaixo e acima da temperatura neutra.

Fonte: Modificada pelos autores, INSTITUTO ..., 2012. 
A sala de aula tem uma área de $78 \mathrm{~m}^{2}$ e capacidade máxima de 83 alunos e, portanto, costuma acomodar turmas com grande quantidade de estudantes. Em todo o edifício, inclusive nessa sala de aula, as áreas envidraçadas são limitadas por vergas, que são as vigas dispostas em todo o contorno do edifício e interrompidas apenas pelos pilares. Tais características ficam mais bem evidenciadas na planta e cortes da sala, conforme mostra a Figura 3.

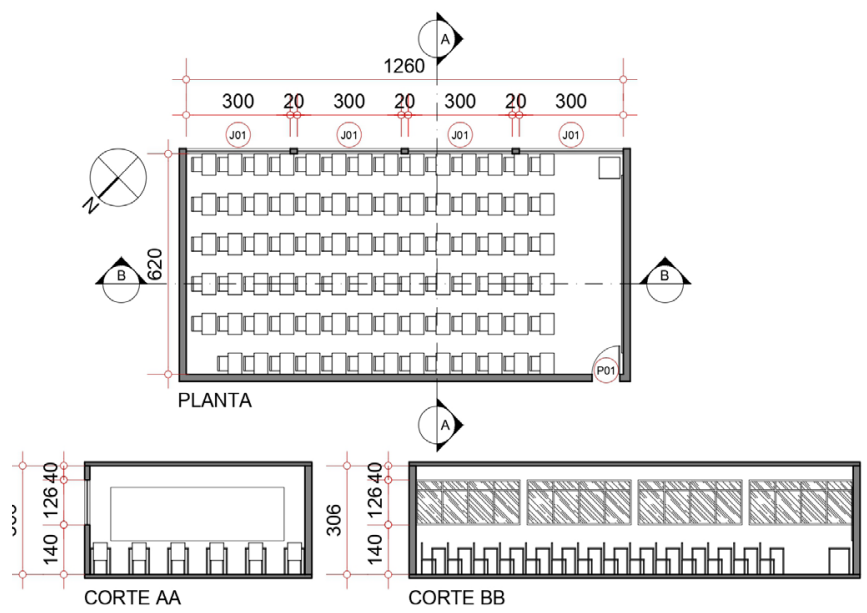

Figura 3 | Planta e corte da sala de aula. Fonte: Elaborada pelos autores, 2019. 
Os relatos dos usuários, feitos de forma verbal à coordenação de curso ao longo dos últimos anos, indicam que a sala apresenta desconforto térmico por causa do calor durante os meses de verão, particularmente incômoda no período noturno. A situação é agravada pela impossibilidade de promover uma ventilação cruzada no ambiente uma vez que as portas devem permanecer fechadas para evitar que o barulho advindo do corredor incomode o desenvolvimento das atividades acadêmicas. É importante observar que as janelas possuem altura de peitoril de $1,40 \mathrm{~m}$ em relação ao piso, o que não permite a ventilação ao nível dos corpos dos usuários, podendo também ser uma das causas do desconforto térmico relatado pelos usuários. O pé-direito do cômodo é de 3,06m. A partir desses relatos, decidiu-se verificar, por meio de simulação computacional, o nível de conforto desse ambiente.

O horário de ocupação da sala de aula é de 7 h às 23 h30, tendo suas atividades interrompidas por duas horas no período de $17 \mathrm{~h}$ às $19 \mathrm{~h}$ para limpeza. A capacidade máxima é de 83 alunos, mas a média de ocupação é de 60 alunos por turma.

\subsection{Modelagem, simulações do ambiente e dados de entrada}

A modelagem do ambiente foi elaborada através do programa SketchUp versão 8.0, com o plug-in OpenStudio. 
Para simulação computacional, foi utilizado o programa EnergyPlus versão 8.7 (FIGURA 4). Para o processamento das simulações, foi utilizado o arquivo climático de 8.760 horas da cidade de Belo Horizonte - Pampulha, com extensão TRY (LABEEE, 2019).

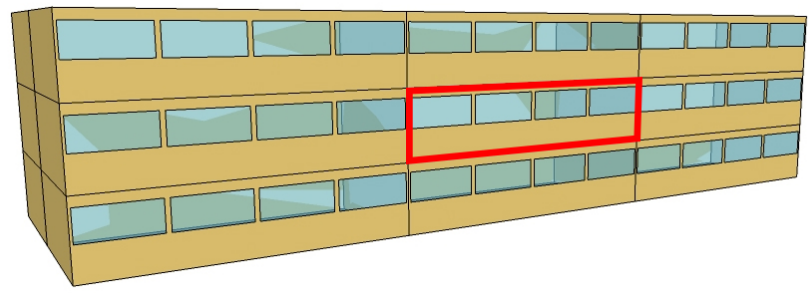

Figura 4 | Modelo desenvolvido no Sketch Up (versão 8) com plug-in OpenStudio. Em vermelho a sala analisada.

Fonte: Elaborada pelos autores, 2019.

As paredes internas e as lajes foram consideradas adiabáticas, visto que se analisou a sala do pavimento intermediário que se encontra rodeada de salas semelhantes. Os dados de condutividade térmica, densidade, calor específico e absortância para radiação solar dos materiais dos componentes construtivos da sala utilizados na simulação correspondem aos valores médios extraídos da NBR 15.220-2 (ASSOCIAÇÃO..., 2005), e podem ser vistos na Tabela 1. 


\begin{tabular}{|l|c|c|c|c|c|}
\hline Material & $\begin{array}{c}\text { Espessura } \\
(\mathbf{m})\end{array}$ & $\begin{array}{c}\text { Condutividade } \\
\text { térmica }[\mathbf{W} / \mathbf{m} \cdot \mathbf{K}]\end{array}$ & $\begin{array}{c}\text { Densidade } \\
{\left[\mathbf{k g} / \mathbf{m}^{3}\right]}\end{array}$ & $\begin{array}{c}\text { Calor } \\
\text { específico } \\
{[\mathbf{J} / \mathbf{k g} \cdot \mathbf{K}]}\end{array}$ & $\begin{array}{c}\text { Absor- } \\
\text { tância }\end{array}$ \\
\hline Tijolo maciço & 0,10 & 0,90 & 1900 & 920 & 0,80 \\
\hline Argamassa & 0,01 & 1,15 & 1950 & 1000 & - \\
\hline Vidro & 0,006 & 1,00 & 2500 & 840 & 0,20 \\
\hline Lã de vidro & 0,02 & 0,045 & 55 & 700 & - \\
\hline Cor do tijolinho & - & - & - & - & 0,80 \\
\hline
\end{tabular}

Tabela 1 | Características dos materiais utilizados na simulação computacional. Fonte: Modificada pelos autores de ASSOCIAÇÃO..., 2005.

Foi considerada a presença de ventilação natural, sendo mantidas abertas as janelas durante todo o período de ocupação da sala de aula. O módulo do EnergyPlus utilizado para tal análise foi o AirFlowNetwork. O horário para avaliação do percentual de conforto correspondeu ao intervalo de ocupação da sala, considerando-se aulas durante a semana, de $2^{\mathrm{a}}$ a $6^{\mathrm{a}}$ feira.

\subsection{Propostas de melhorias}

Com o intuito de proporcionar aumento de conforto térmico para a sala de aula, foram propostas alterações arquitetônicas consideradas como viáveis de serem executadas. O ambiente real foi simulado para servir de base de comparação para as soluções propostas para a edificação (simulação 1). Em seguida simulou-se a introdução de brise soleils dimensionados para reduzir a incidência de radiação solar direta na área envidraçada. Foram propostas duas dimensões de brises horizontais: a primeira, 
com inclinação de $30^{\circ}$ (simulação 2), e a segunda, com inclinação de $60^{\circ}$ (simulação 3). Simulou-se, ainda, a alteração da pintura das paredes externas para a cor branca, de modo a reduzir a absortância solar da fachada (simulação 4). Na simulação 5, propôs-se isolar a face interna da parede da fachada externa com lã de vidro para aumentar a resistência térmica das paredes. As simulações de 6 a 10 mesclaram as soluções anteriormente citadas. Dessa forma, foram determinadas quatro soluções e avaliada a combinação entre elas, totalizando 10 simulações conforme descrito na Tabela 2.

\begin{tabular}{|l|l|l|l|l|l|l|l|l|l|l|}
\hline Propostas / Simulação & $\mathbf{1}$ & $\mathbf{2}$ & $\mathbf{3}$ & $\mathbf{4}$ & $\mathbf{5}$ & $\mathbf{6}$ & $\mathbf{7}$ & $\mathbf{8}$ & $\mathbf{9}$ & $\mathbf{1 0}$ \\
\hline Situação atual & $\mathrm{X}$ & & & & & & & & & \\
\hline Brise Soleil 30 & & $\mathrm{X}$ & & & & $\mathrm{X}$ & $\mathrm{X}$ & & & \\
\hline Brise Soleil 60 & & & $\mathrm{X}$ & & & & & $\mathrm{X}$ & $\mathrm{X}$ & \\
\hline Paredes externas pintadas de branco & & & & $\mathrm{X}$ & & $\mathrm{X}$ & & $\mathrm{X}$ & & $\mathrm{X}$ \\
\hline Isolamento da parede com lã de vidro (500mm) & & & & & $\mathrm{X}$ & & $\mathrm{X}$ & & $\mathrm{X}$ & $\mathrm{X}$ \\
\hline
\end{tabular}

Tabela 2 | Características dos materiais utilizados na simulação computacional. Fonte: Elaborada pelos autores, 2019.

\subsection{Requisitos de análise de desconforto conforme a ASHRAE 55}

A ASHRAE 55 é uma norma americana que tem como objetivo caracterizar as condições ambientais térmicas aceitáveis para a maioria dos ocupantes através de métodos de avaliação para ambientes internos (ASHRAE, 2013). 
Um dos métodos empregados por ela é o método adaptativo. Esse método é utilizado para edificações naturalmente ventiladas, como no caso do ambiente analisado nesta pesquisa. Ele considera que os ocupantes têm liberdade de fazer ajustes corporais, como adaptar suas vestimentas de acordo com às condições térmicas internas e/ou externas. A norma define limites superior e inferior de temperatura para níveis de aceitabilidade de $80 \%$ e 90\% dos usuários, conforme Figura 5.

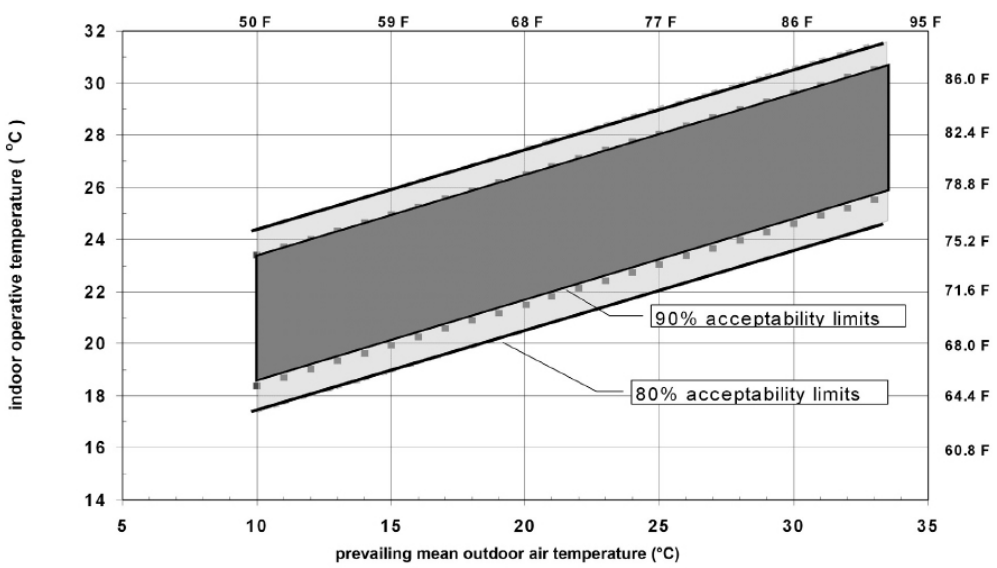

Figura 5 | Faixas de temperatura operativa aceitável para espaços naturalmente condicionados.

Fonte: ASHRAE, 2013. 
As equações 1 e 2 apresentam, respectivamente, as equações referentes aos limites inferiores e superiores de aceitabilidade térmica do modelo adaptativo na ASHRAE 55 (ASHRAE, 2013). A temperatura média do ar externo predominante é calculada a partir da média da temperatura do ar externo, considerando, no mínimo, sete dias e, no máximo, 30 dias sequenciais ao dia analisado.

$$
\begin{aligned}
& T_{\text {limite superior }}=0,31 \overline{T_{\text {pma(out })}}+21,3\left({ }^{\circ} \mathrm{C}\right) \text { Equação } 1 \\
& T_{\text {limite inferior }}=0,31 \overline{T_{\text {pma(out })}}+14,3\left({ }^{\circ} \mathrm{C}\right) \quad \text { Equação } 2
\end{aligned}
$$

Sendo: $\overline{T_{\text {pma(out) }}}$ a temperatura média do ar externo predominante.

\subsection{Percentual das horas ocupadas em conforto se- gundo o RTQ-C}

Para a obtenção da classificação dos ambientes naturalmente ventilados, o Regulamento Técnico da Qualidade para o Nível de Eficiência Energética de Edificações Comerciais, de Serviços e Públicas (RTQ-C) determina que a análise deva ser feita por meio da simulação computacional. O RTQ-C exige que sejam seguidos os critérios da ISO 7730 ou da ASHRAE 55 para obtenção dos índices de conforto para os ambientes, bem como o atendimento às normas da ABNT de conforto acústico vigentes. Para saber se esses ambientes estão atendendo aos limites estabelecidos, a ASHRAE 55 estabelece que se deve 
calcular a temperatura operativa de cada ambiente (zona térmica) nas 8.760 horas do ano. Com os cálculos feitos, compara-se a temperatura operativa do ambiente com os limites estabelecidos pela ASHRAE 55 e, assim, obtém-se o percentual das horas ocupadas em conforto (POC). A classificação do ambiente é baseada no valor do POC encontrado conforme descrito na Tabela 3. Essa classificação de cada ambiente naturalmente ventilado varia de A (mais eficiente) a $E$ (menos eficiente) (INSTITUTO..., 2010).

\begin{tabular}{|c|c|c|}
\hline $\begin{array}{l}\text { Percentual de Horas } \\
\text { Ocupadas em Conforto }\end{array}$ & Classificação final & Cor referenciada \\
\hline POC $\geq 80 \%$ & A & Verde escuro \\
\hline $70 \% \leq \mathrm{POC}<80 \%$ & B & Verde claro \\
\hline $60 \% \leq \mathrm{POC}<70 \%$ & C & Amarelo \\
\hline $50 \% \leq \mathrm{POC}<60 \%$ & D & Laranja \\
\hline $\mathrm{POC}<50 \%$ & E & Vermelho \\
\hline
\end{tabular}

Tabela 3 | Classificação conforme Percentual de Horas Ocupadas em Conforto (POC). Fonte: Modificada pelos autores de INSTITUTO..., 2010.

Considera-se que essa seja uma métrica de fácil entendimento por parte do usuário, mais intuitiva que a métrica de graus-hora de desconforto analisada também por normas brasileiras e por isso, será utilizada no presente trabalho.

Foi ainda simulado o consumo de energia de um sistema 
de ar-condicionado do tipo split, auto dimensionado no programa EnergyPlus. Tal estratégia visou analisar o impacto no consumo de energia das estratégias propostas caso se optasse por introduzir na sala um sistema de condicionamento artificial de ar. Para essa análise, as janelas foram consideradas sempre fechadas.

\section{Análise de resultados}

Os resultados obtidos foram compilados apresentado no Grafico 1. O gráfico apresenta na legenda à esquerda a classificação energética conforme o POC do RTQ-C mostrada para cada caso através das cores relativas a cada classificação. Pode-se verificar no Gráfico 1 que a situação atual apresentou apenas $50 \%$ das horas ocupadas em conforto ao longo do ano o que leva a uma classificação D junto ao RTQ-C.

Pode-se verificar ainda que todas as estratégias propostas quando consideradas isoladamente, à exceção daquela relativa ao isolamento da parede, apresentaram aumento do percentual de horas em conforto. Era esperado que, com uma alta carga interna de ocupação, o isolamento das paredes prejudicasse a perda de calor no período da noite quando a sala estivesse desocupada. Tal comportamento foi verificado também na conjugação das propos- 
tas sugeridas ao isolamento da parede em que se obteve um percentual de conforto inferior a $50 \%$ (estratégias 9 e 10) o que resultaria numa classificação $E$ junto ao RTQ-C. Apenas na conjugação com o brise de $30^{\circ}$ de inclinação houve manutenção do percentual de conforto quanto a análise da estratégia isolada (53\% das horas de conforto). Essa solução de isolamento da parede foi testada pois era uma das soluções possíveis levantadas pelos professores da instituição. Entretanto, a análise de seu comportamento por meio de simulação computacional fornece ao tomador de decisão um dado preciso relativo a não indicação dessa estratégia, haja vista que o número de horas de conforto seria menor com a sua aplicação. 

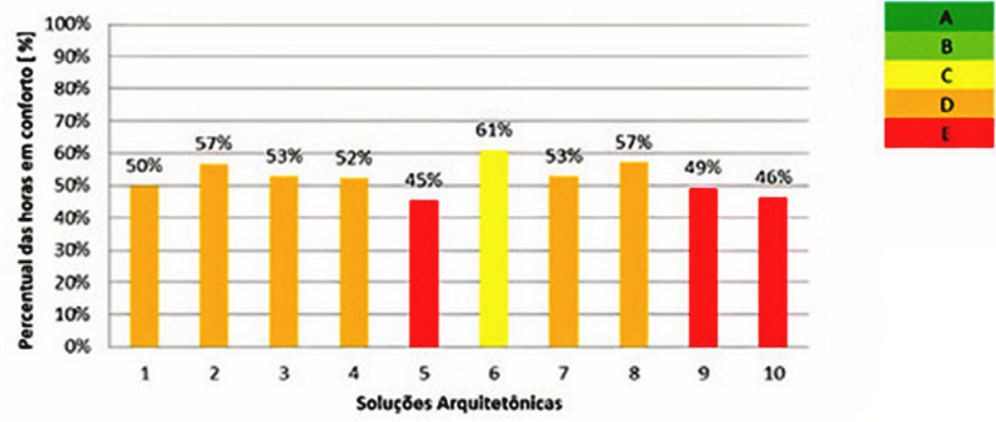

302 Legenda:

1 - Situação atual

2 - Brise Soleil $30^{\circ}$

3 - Brise Soleil $60^{\circ}$

4 - Paredes externas pintadas de branco

5 - Isolamento com lả de vidro $500 \mathrm{~mm}$

6 - Brise Soleil $30^{\circ}+$ paredes externas pintadas de branco

7 - Brise Soleil $30^{\circ}+$ isolamento com lä de vidro $500 \mathrm{~mm}$

8 - Brise Soleil $60^{\circ}+$ paredes externas pintadas de branco

9 - Brise Soleil $60^{\circ}+$ isolamento com lã de vidro $500 \mathrm{~mm}$

10 - Paredes externas pintadas de branco + isolamento com lã de vidro $500 \mathrm{~mm}$

Gráfico 1 | Resultados das soluções arquitetônicos propostas x percentual de horas de conforto.

Fonte: Elaborado pelos autores, 2019. 
Verifica-se ainda pelo Gráfico 1 que apenas a solução 6, na qual foi conjugada a pintura das paredes externas com um brise de $30^{\circ}$ de inclinação, obteve um percentual de conforto superior a $60 \%$, com uma classificação C junto ao RTQ-C.

Dentre as soluções com adição de brise soleils nas fachadas, aquela que apresenta inclinação de $30^{\circ}$ obteve melhor desempenho comparado com os valores obtidos para o brise soleil com inclinação de $60^{\circ}$. É interessante observar que a solução em que se instala o brise soleil com inclinação de $60^{\circ}$ (simulação 3) obteve praticamente o mesmo percentual de horas de conforto que a solução de pintar as paredes externas na cor branca (simulação 4), considerada, economicamente, uma solução mais viável.

Conforme Rizzo e Sardeiro (2017) que afirmaram as soluções combinadas com as proteções solares serem capazes de melhorar os resultados, as combinações da pintura das paredes com brise soleil de $30^{\circ}$ e $60^{\circ}$ (correspondente às simulações 6 e 8) foram as soluções que apresentaram maior percentual de horas em conforto, com valores respectivos de $61 \%$ e de $57 \%$. 
Assim como apontaram Costa, Joko e Frederico (2017), em nenhuma solução foi possível atender ao valor de $80 \%$ de horas de conforto conforme determinado pelo RTQ-C para obtenção de classificação $A$, de acordo com os parâmetros estabelecidos pela ASHRAE 55. Tal se deve à alta densidade de ocupação da sala analisada, cujos ocupantes geram expressiva carga térmica para o ambiente e ao fato de que não há ventilação cruzada no ambiente, pois do outro lado do corredor há mais um conjunto de salas de aula.

O Gráfico 2 apresenta o consumo de energia elétrica obtido no caso base e em cada uma das alterações de projeto propostas. Pode-se verificar no Gráfico 2 que a situação atual apresentou consumo anual de energia correspondente a $168 \mathrm{kWh} / \mathrm{m}^{2} / \mathrm{ano}$ e a melhor solução encontrada para o conforto térmico (solução 6) foi também a que menos consumiu energia - $160 \mathrm{kWh} / \mathrm{m}^{2} / \mathrm{ano}$. Verifica-se, ainda, que a solução de menor POC foi também aquela que teve o maior consumo de energia elétrica. 


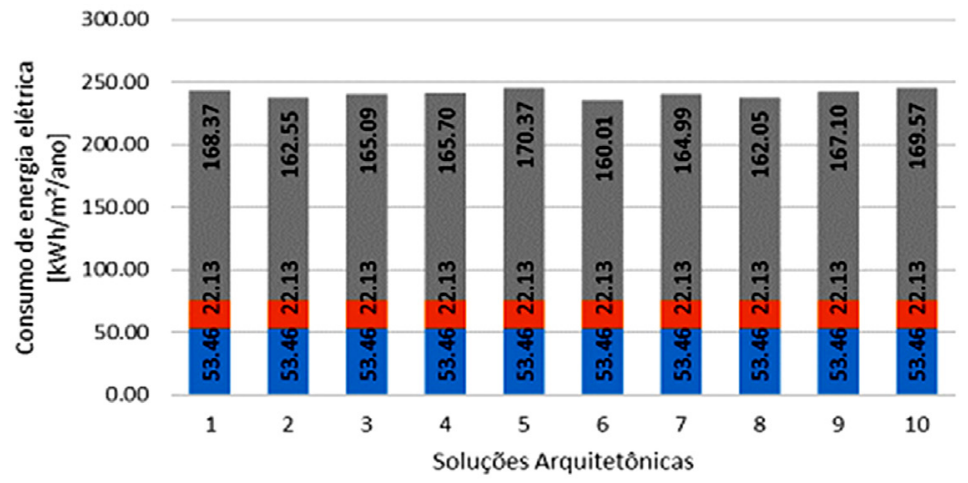

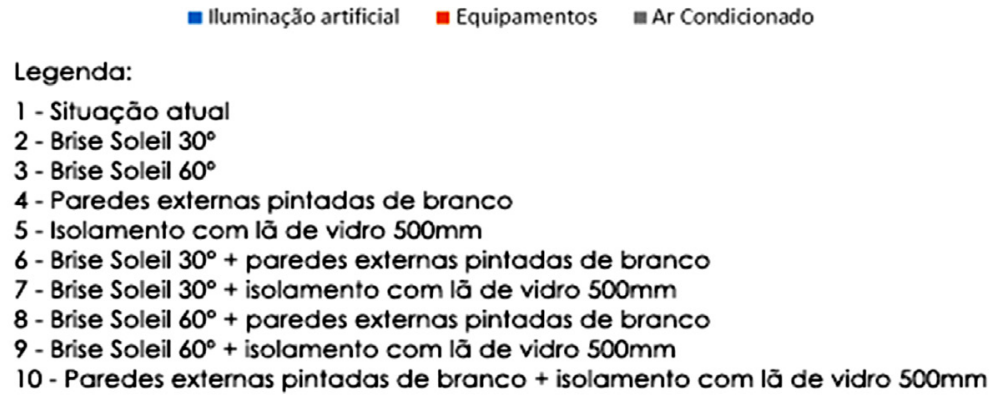

Figura 2 | Resultados das soluções arquitetônicos propostas x consumo de energia.

Fonte: Elaborado pelos autores, 2019. 
Percebe-se que, ainda assim, as propostas de alterações passivas possibilitariam redução do desconforto térmico e propiciariam redução no eventual consumo de energia elétrica caso fosse instalado um sistema de condicionamento artificial de ar, com um potencial máximo de 5,0\% quando aplicada a solução 6 que conjuga a presença de brises e pintura da parede externa. Deve-se levar em consideração que, para o consumo de energia, apenas foi considerada uma carga constante de equipamentos e iluminação nos horários de uso da sala.

\section{Conclusões}

O trabalho apresentou propostas de alterações arquitetônicas e avaliou a sua influência para o conforto térmico de uma sala de aula existente por meio de simulação computacional. Nenhuma das alterações propostas alcançou o desempenho estabelecido para classificação $A$ de acordo com o RTQ-C, de $80 \%$ de horas de conforto. Entretanto, foi encontrada solução combinada que alcançou valor percentual de $61 \%$ de horas de conforto (simulação 6), correspondentes ao nível $\mathrm{C}$ de classificação. Os resultados mostraram que as soluções bioclimáticas devem ser tomadas no início do projeto pois após o edifício ter sido construído o potencial de melhoria pode ser considerado relativamente baixo, uma vez que não é possível mais se introduzir a ventilação cruzada, por exemplo. 
Importante ressaltar que o ambiente apresenta uma população média de 60 pessoas, sem a possibilidade da presença de ventilação cruzada. Dessa forma, recomendam-se soluções de condicionamento artificial como o uso de ventiladores e/ou de sistema de condicionamento artificial do ar para a obtenção de conforto nos horários em que a temperatura ficou acima dos limites de norma.

Esse ambiente representa uma situação real, mas que é também representativa de outros ambientes construídos encontrados em edifícios escolares da mesma instituição. Acredita-se que essas soluções arquitetônicas possam ser desenvolvidas e avaliadas como opções de retrofit e que os melhores resultados poderiam ser obtidos ainda em projeto, antes da construção das edificações a fim de verificar e proporcionar os melhores níveis de conforto térmico aos usuários. Para tal, a simulação computacional se mostra como um poderoso aliado e deveria ser considerada na contratação dos projetos.

\section{Referências}

ASSOCIAÇÃO BRASILEIRA DE NORMAS TÉCNICAS.

NBR 15220-2: Desempenho térmico de edificações Parte 2: Métodos de cálculo da transmitância térmica, da capacidade térmica, do atraso térmico e do fator solar de elementos e componentes de edificações. Rio de Janei- 
ro: ABNT, 2005.

ASHRAE - AMERICAN SOCIETY OF HEATING, REFRIGERATING AND AIR-CONDITIONING ENGINEERS. Thermal Enviromental Conditions for Human Occupancy. Atlanta, 2013. p.58.

BACICHETI, R; CARDOSO, L; SARDEIRO, P. Desempenho geométrico de um brise soleil: um estudo sobre seu impacto na iluminação e ventilação natural em uma sala de aula. In: XVI Encontro Nacional de Tecnologia do Ambiente Construído, São Paulo, 2016, Anais...São Paulo.

BATIZ, E. C. et al. Avaliação do conforto térmico no aprendizado: estudo de caso sobre influência na atenção e memória. Produção, São Paulo, v. 19, n. 3, p. 477-488, set./ dez. 2009.

BRASIL. Empresa de Pesquisa Energética. Balanço Energético Nacional 2018 - ano base: 2017: relatório síntese. Rio de Janeiro: EPE, 2018. 62 p.

COSTA, L. R. JOKO, C.; FREDERICO, C. Simulação termoenergética de edifício educacional histórico naturalmente ventilado na cidade de Brasília. In: XIV Encontro Nacional e X Latino Americano de Conforto no Ambiente Construído, Balneário Camboriú, Brasil, 2017, Anais...Balneário Camboriú. 
HEYWOOD, H. 101 regras básicas para edifícios e cidades sustentáveis. São Paulo: Editorial Gustavo Gili, 2017

GARCIA, M. S. Metodologia para desenvolvimento de benchmarking para edifícios de uso universitário baseado em critérios de eficiência energética e conforto térmico. Qualificação de Doutorado, Curso de Pós Graduação em Ambiente Construído e Patrimônio Sustentável, UFMG, Belo Horizonte, 2019.

INSTITUTO NACIONAL DE METROLOGIA, NORMALIZAÇÃO E QUALIDADE INDUSTRIAL. Portaria $\mathbf{n}^{\circ} \mathbf{3 7 2}, 17$ de setembro de 2010. Regulamento Técnico da Qualidade para o Nível de Eficiência Energética de Edificações Comerciais, de Serviços e Públicas (RTQ-C). Rio de Janeiro, 2010. Disponível em: <http://www.pbeedifica.com.br/ sites/default/files/projetos/etiquetagem/comercial/downloads/Port372-2010_RTQ_Def_Edificacoes-C_rev01.pdf>. Acesso em: 6 abr. 2019.

INSTITUTO NACIONAL DE METROLOGIA, NORMALIZAÇÃO E QUALIDADE INDUSTIRAL. Portaria $\mathbf{n}^{\mathbf{0}} \mathbf{1 8}, 16$ de janeiro de 2012. Regulamento Técnico da Qualidade para o Nível de Eficiência Energética de Edificações Residenciais (RTQ-R). Rio de Janeiro, 2012. Disponível em: <http:// www.inmetro.gov.br/legislacao/rtac/pdf/RTAC001788. pdf> Acesso em: 6 abr. 2019.

KEELER, M.; BURKE, B. Fundamentos de projeto de 
edificações sustentáveis. Porto Alegre: Bookman, 2010.

LAMBERTS, R.; DUTRA, L.; PEREIRA, F. O. R. Eficiência Energética na Arquitetura. 3a edição. Rio de Janeiro: Eletrobras; Procel; Procel Edifica, 2014. 366 p.

LABEEE, M. Arquivos climáticos em formato TRY, SWERA, CSV e BIN. Disponível em: <http://www.labeee.ufsc.br/downloads/arquivos-climaticos/formato-try-swera-csv-bin>. Acesso em: 6 abr. 2019.

OCHOA, J. H.; ARAÚJO D. L.; SATTLER M. A. Análise do conforto ambiental em salas de aula: comparação entre dados técnicos e a percepção do usuário. Ambiente Construído, Porto Alegre, v. 12, n. 1, jan./mar.2012.

RIZZO, R. B.; SARDEIRO, P. Conforto térmico em salas de aula de tipologia similar: influência do entorno. In: XIV Encontro Nacional e X Latino Americano de Conforto no Ambiente Construído, Balneário Camboriú, Brasil, 2017, Anais...Balneário Camboriú.

ROGERS, R. Cidades para um pequeno planeta. BarceIona: Editorial Gustavo Gili, 1997.

SINGH, M. K. et al. Progress in thermal comfort studies in classrooms over last 50 years and way forward. Energy and Buildings, v. 188-189, p. 149-174, 2019. 
VASCONCELOS D. B.; MENEZES, D. K. T.; BARBOSA, R. $V$. R. Análise térmica em ambientes de ensino: um estudo de caso no Campus UFAL Arapiraca. In: XIV Encontro Nacional e X Latino Americano de Conforto no Ambiente Construído, Balneário Camboriú, Brasil, 2017, Anais...Balneário Camboriú 